NBER WORKING PAPER SERIES

\title{
INEQUALITY OF SUBJECTIVE WELL-BEING AS A COMPREHENSIVE MEASURE OF INEQUALITY
}

\author{
Leonard Goff \\ John F. Helliwell \\ Guy Mayraz \\ Working Paper 21900 \\ http://www.nber.org/papers/w21900 \\ NATIONAL BUREAU OF ECONOMIC RESEARCH \\ 1050 Massachusetts Avenue \\ Cambridge, MA 02138 \\ January 2016, Revised July 2019
}

\begin{abstract}
All three authors are grateful for research support from the Canadian Institute for Advanced Research, through its program on Social Interactions, Identity and Well-Being. We are also grateful to Gallup for access to data from the Gallup World Poll and the Gallup-Healthways Well-Being Index. We thank Paul Frijters, Carol Graham, Richard Layard, Eric Snowberg, Joe Stiglitz, and the anonymous referees for helpful comments on an earlier version. This paper was first circulated under the title "The Welfare Costs of Well-being Inequality." The views expressed herein are those of the authors and do not necessarily reflect the views of the National Bureau of Economic Research.
\end{abstract}

NBER working papers are circulated for discussion and comment purposes. They have not been peer-reviewed or been subject to the review by the NBER Board of Directors that accompanies official NBER publications.

(C) 2016 by Leonard Goff, John F. Helliwell, and Guy Mayraz. All rights reserved. Short sections of text, not to exceed two paragraphs, may be quoted without explicit permission provided that full credit, including $\odot$ notice, is given to the source. 
Inequality of Subjective Well-Being as a Comprehensive Measure of Inequality

Leonard Goff, John F. Helliwell, and Guy Mayraz

NBER Working Paper No. 21900

January 2016, Revised July 2019

JEL No. D6,D63,I31

\section{$\underline{\text { ABSTRACT }}$}

The link between happiness and overall inequality is best studied using an index that incorporates different aspects of inequality, and is measured consistently in different countries. One such index is the degree to which happiness itself varies among individuals. Its correlation with both happiness levels and social trust is substantially stronger than the corresponding correlation for income inequality. This remains so after allowing for bounded scale reporting, including a purely ordinal measure of dispersion. Moreover, the correlation is stronger for individuals who profess to care most about inequality. The link between happiness and inequality may thus be stronger than previously appreciated.

Leonard Goff

Department of Economics

Columbia University

420 W. 118th Street, MC 3308

New York, NY 10027

leonard.goff@columbia.edu

John F. Helliwell

Vancouver School of Economics

University of British Columbia

6000 Iona Drive

Vancouver, BC V6T 1L4

CANADA

and NBER

john.helliwell@ubc.ca
Guy Mayraz

Department of Economics

University of Melbourne

111 Barry Street

Carlton VIC 3010

AUSTRALIA

guy.mayraz@unimelb.edu.au 


\section{INTRODUCTION}

Current research into the impact of inequality on happiness is focused on income inequality, typically using the Gini coefficient of income as a proxy for the level of inequality in a given state or country. ${ }^{1}$ This strategy has yielded important insights, but it also has important limitations. People care not only about inequality in income, but also about inequality in other domains, such as legal rights, education, health, economic opportunities, housing, and social networks. ${ }^{2}$ Even if we restrict attention to income, differences in how long or how hard people choose to work can obscure differences in their true economic opportunity set. There are further problems in comparing the level of inequality in different countries. The definition of income varies across countries, as does the portion of personal consumption that individuals fund themselves. ${ }^{3}$ These factors introduce noise into the link between overall inequality and the particular indicators (such as the Gini coefficient) that we use in regressions. When using income inequality as a regressor, we would obtain a bias towards zero- underestimating how strongly happiness and inequality are related. In addition, we would lose statistical power, reducing our ability to study small samples or use demanding econometric techniques.

One approach to overcoming these limitations is to include additional regressors to represent inequality in other domains. But if our measure of income inequality is problematic, measuring inequality in other domains is not going to be any easier. The alternative is to look for an indicator of the quality of life in its entirety, and use the dispersion of this indicator as the measure of inequality in a given society. Satisfaction with life (SWL) is such an indicator. SWL is an index of well-being that incorporates all the different aspects of life that the person cares about with the weights that he or she ascribes to them. It is high if a person's life is good, and is low if her life is bad. At the societal level, SWL represents the distribution of (self-evaluated) life quality in that society. SWL is high if life is good for members of that society, and is low

\footnotetext{
${ }^{1}$ Alesina et al. (2004) - the best known paper in this field - is a good example of this approach. Recently, Burkhauser et al. (2016) has retained the focus on income inequality, but replaced the Gini coefficient with a measure of income concentration at the top of the distribution.

${ }^{2}$ For a discussion of these forms of inequality see Piketty (2014), Neal and Rick (2014), Wang and Parker (2014), Case and Deaton (2015).

${ }^{3}$ For example, health, education, and childcare are self funded in some countries, and publicly funded in others.
} 
if their life is not good. Its distribution is relatively concentrated in societies whose members enjoy a similar quality of life, and is relatively dispersed if some parts of society have a much better life than others.

Since SWL incorporates all the aspects of life, its dispersion can be seen as a comprehensive measure of inequality - one that captures not only differences in income, but also differences in leisure, education, legal rights, and other aspects of life. By studying the link between SWL levels and SWL dispersion, we can test whether SWL and inequality are correlated, and in particular whether high levels of inequality are associated with low levels of subjective well-being (Figure 1). Since SWL dispersion is a comprehensive measure of inequality, such a correlation will incorporate the possible impact not only of income inequality, but also of inequality in other life domains.

The underlying causal links may be straightforward, but they could also be quite elaborate. Inequality may cause resentment or sympathy, lowering SWL through a direct causal link. But inequality can also affect SWL indirectly. For example, wealth disparities may engender differences in political influence, which make the poor feel powerless. This feeling of powerlessness can then reduce SWL even if the poor do not resent wealth disparities as such. Indeed, inequality may reduce SWL even if people are not aware of the level of inequality in their society-let alone the level of SWL inequality. ${ }^{4}$

We now have SWL data for about 150 countries going back to 2006, and for at least some countries we have data going back to the 1970s. We are thus able to study the link between SWL levels and SWL dispersion in most of the countries in the world, including countries in which income data is unreliable or altogether missing. There is, however, a potential problem due to the bounded scale on which SWL is reported. If the distribution of reported SWL in countries with relatively high SWL is compressed against the upper bound of the scale, we would obtain a downward bias in the correlation between average SWL and SWL dispersion (Figure 1c). Theoretically, this bias could result in a spurious negative correlation between happiness and inequality. More realistically, it would bias our estimates of the true correlation, leading us to see the negative relationship between happiness and inequality as stronger than it really is. ${ }^{5}$ No measure is perfect, and if this bias is small, the advantages of

\footnotetext{
${ }^{4}$ Some forms of inequality — such as inequality in legal rights - are more visible than others, and hence more likely to have a direct impact on SWL.

${ }^{5}$ Measurement error is less of a concern in this case. In particular, suppose that individual SWL is measured with a normally distributed error. The effect would be to shift the standard deviation of the SWL distribution in each cluster upwards by the standard deviation of the
} 


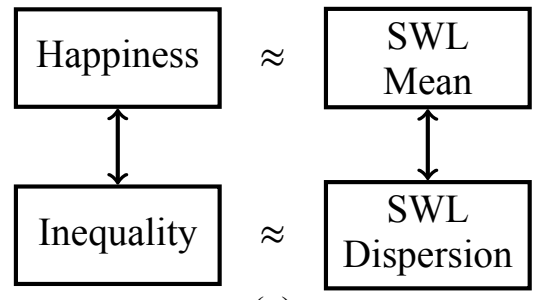

(a)

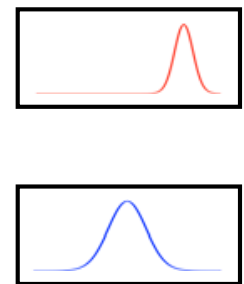

(b)

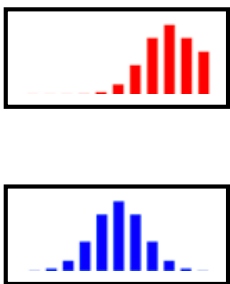

(c)

Figure 1: (a) The level of happiness in a country can be measured by the mean of the distribution of satisfaction with life (SWL), and the level of inequality by its dispersion. (b) A negative correlation between happiness and inequality would result in a negative correlation between the mean and dispersion of the SWL distribution. (c) The bounded scale on which SWL is reported is a potential source of bias: the distribution in high SWL countries is censored, reducing the dispersion through a purely mechanical channel that has nothing to do with the level of inequality.

the SWL dispersion measure of inequality could more than justify its use for studying how SWL and inequality are related. But if the bias is large, we may be better off setting SWL inequality aside, despite all its advantages.

We thus have a powerful and convenient measure of inequality, but it comes with a potentially fatal weakness. Our goal in this paper is to evaluate this weakness: should it be a deal-breaker, or is it a minor issue? Should researchers ignore SWL dispersion, or should they adopt it as the most empirically useful measure of overall inequality?

The measurement of SWL inequality was first proposed by Veenhoven (1990). The World Database of Happiness includes data on the standard deviation of happiness in various countries starting in $1946 .{ }^{6}$ Several papers have studied changes in SWL inequality, ${ }^{7}$ but only a handful have examined its relationship with happiness levels (Delhey, 2004; Ott, 2005; Bolle et al., 2009; Quick, 2015). All these studies have reported a strong negative correlation between the two. For example, Ott (2005) studied a sample of 78 countries in the World Values Survey, and found a strong correlation of $r=-0.65$ between the mean and standard deviation of the SWL distribution. Ott considered the

noise, making no difference whatsoever to regression results.

${ }^{6}$ See trend report in https://worlddatabaseofhappiness.eur.nl/hap_nat/findingreports/ TrendReport_InequalityHappiness.pdf.

${ }^{7}$ Perhaps best known is the Stevenson and Wolfers (2008) study of well-being inequality in the United States. 
possibility that the correlation is purely mechanical, but dismissed it on the grounds that it remained negative $(r=-0.29)$ in the subsample of relatively poor countries with GDP per capita of less than $\$ 10,000$. Ott's argument was that the mean happiness in this group of countries was relatively distant from the upper bound of the reporting scale, and that a mechanical relationship was therefore unlikely. ${ }^{8}$ Quick (2015) also considered the mechanical correlation problem, and concluded that "a much deeper understanding of these issues will be required if well-being inequality is to be used robustly in the policy making process."

While the main contribution of this paper is to evaluate the possibility that the observed correlations are largely (or even entirely) mechanical, we start by establishing a baseline of correlations in a number of different surveys: the European Social Survey, the World Values Survey, the Gallup World Poll, and the Gallup-Healthways Well-Being Index (comparing U.S. states). Taken together, these surveys include over 160 countries and (for some of these countries) survey waves from 1990 to 2015. In order to regress SWL levels on SWL dispersion we need to represent each of them with a single number. We use the mean of the SWL distribution as our measure of SWL levels, and the standard deviation as our measure of SWL dispersion. As a robustness check, we investigate a purely ordinal measure of dispersion in Appendix A.

We estimate individual level regressions in clusters defined by the combination of country/wave (state/wave in the Gallup-Healthways Well-Being Index), and controls for log GDP per capita (in PPP terms), region dummies, and personal variables: gender, age, education, employment, and marital status. Despite the inclusion of these controls, we replicate earlier findings of a strong and strongly statistically significant negative relationship between SWL levels and dispersion in all the surveys.

If SWL dispersion does a better job of representing overall inequality than do measures of income inequality, we would expect its correlation with SWL levels to be stronger. We estimate corresponding regressions with income inequality replacing SWL dispersion, and confirm that this is indeed the case. Moreover, when we include both measures of inequality in the same regression, the coefficient on income inequality is substantially reduced in magni-

\footnotetext{
8“"This negative correlation between level and inequality is, up to a point, a 'ceiling effect' since it is inevitable that inequality, as measured by standard deviation, will diminish if higher average levels are reached. But this correlation is also visible in poor countries with lower average levels and this arithmetical necessity does not predict that it really happens!" (Ott, 2005)
} 
tude, but the coefficient on SWL dispersion is unchanged.

Though interesting, these results do nothing to address the possibility of a mechanical correlation bias. We evaluate this possibility with the help of three tests. The first exploits questions - available in two of the surveys we use - that ask respondents whether they think income differences should be reduced. We take this question as a measure of aversion to inequality, and test whether the correlation between SWL levels and dispersion in subjects averse to inequality is stronger than the corresponding correlation in other subjects. We find that this difference is large and statistically significant. These results are hard to reconcile with a purely mechanical correlation - which should not differ between subjects who care about inequality and those who don't, and are exactly what we would expect if the correlation between SWL levels and dispersion measures the true relationship between happiness and inequality.

Our second test uses a partialling out logic to control directly for the mechanical correlation effect. We regress social trust on SWL inequality, and measure the change in the coefficient when we add mean SWL as an additional regressor. Social trust is important for both happiness (Helliwell \& Putnam, 2004; Helliwell \& Wang, 2011) and economic growth (Knack \& Keefer, 1997), and is strongly correlated with income inequality (Bjørnskov, 2007; Rothstein \& Uslaner, 2005). To the extent that SWL inequality measures overall inequality, we would expect it to be correlated with social trust, and the correlation coefficient should not significantly depend on whether mean SWL is a regressor. By contrast, the mechanical component of the correlation with SWL inequality is driven by mean SWL, and should disappear when conditioning on the cluster mean of SWL. The results are that the coefficient on SWL inequality is barely changed if mean SWL is added to the regression, consistent with the real correlation interpretation. In the Gallup World Poll we also examine other well-being determinants: recent feelings of worry and stress, and whether the respondent feels safe walking alone. Again we find strong correlations with SWL inequality in the expected direction (more worry, stress, and fear of walking alone), and only a small decline in the coefficient when mean SWL is added as a regressor. These results suggest that the correlations with SWL inequality are almost entirely due to real correlations with overall inequality, with only a very small role for a mechanical correlation effect.

Our third test is to estimate a bound on the size of the mechanical correlation on the assumption that the distribution of actual SWL extends beyond the range on which SWL can be reported, and individuals choose the closest integer to their actual SWL within the bounds of the reporting scale. The dis- 
tribution of reported SWL in clusters with a high mean SWL is left skewed, with a large majority of people reporting SWL values in the upper part of the scale, a long left tail, and a much smaller right tail. If the distribution of actual SWL is also left-skewed, there would be little or no censoring of actual values at the upper end of the scale, and little or no mechanical correlation between SWL levels and SWL dispersion. But if the distribution of actual SWL is symmetric and unbounded, the right tail would have to extend far beyond the end of the scale to mirror the distribution within the reporting scale. Since reported values are censored at ten, this would result in a large mechanical correlation between SWL levels and SWL dispersion. Thus, an unbounded symmetric distribution represents a reasonable "worst-case" for estimating the possible extent of this mechanical correlation. We assume that the distribution of actual SWL is logistic (the relatively fat tailed logistic distribution offers a better fit than a normal distribution). We find the maximum likelihood mean and variance for each cluster, and compute the correlation between SWL levels and SWL dispersion in actual SWL space. The correlation is about a third smaller than the correlation in reported SWL space, suggesting that at least two thirds of the correlation in reported SWL space is real, and cannot be explained away as an artifact of the bounded reporting scale.

Finally, as an alternative to modelling the SWL reporting function we reestimate our main regressions using an ordinal measure of dispersion - the variation ratio (the proportion of observations not equal to the mode). Since this is a weaker measure of dispersion than the standard deviation, we expect the correlation to be weaker. Nevertheless, we obtain qualitatively the same results, providing yet more evidence that the correlation between SWL levels and SWL dispersion is real.

We thus conclude that mechanical correlation plays only a small role in explaining the strong negative correlation between SWL levels and dispersion, and is by no means a deal-breaker. Most of the correlation is real, suggesting (i) that the degree of SWL dispersion is indeed a useful measure of overall inequality, and (ii) that the true cross-country correlation between happiness and overall inequality is large. Consider the magnitude of changes associated with a one point increase in SWL. While the exact coefficients vary among the surveys, a one point change in SWL on a $0-10$ scale is associated either with a tripling of GDP per capita, or with a one point decrease in the standard deviation of SWL. As an example, New Zealand's GDP per capita is about $35 \%$ lower than in the United States, and the standard deviation of SWL is about 0.3 points less. According to our estimated coefficients, these two dif- 
ferences in wealth and inequality are associated with comparable differences in happiness. Indeed, according to the Gallup World Poll, the mean SWL in 2014 in the US was 7.28 and in New Zealand it was a nearly identical 7.35. Denmark - the country with the world's highest mean SWL level of 7.58 has about the same GDP per capita as the United States and about the same SWL dispersion as New Zealand. Our findings do not imply that the correlation between happiness and overall inequality is causal, but they do suggest that researchers interested in the relationship between happiness and inequality use SWL dispersion as their measure of overall inequality.

\section{DATA}

Section II.1 provides a general discussion of satisfaction with life data, and the inter-personal comparability assumptions that are required in its analysis. Section II.2 explains our use of the standard deviation to measure SWL dispersion. Section II.3 describes the SWL surveys we use. Section II.4 details our sources for supporting macro data.

\section{II.1 Satisfaction with life}

We use the term satisfaction with life (SWL) to refer to a person's overall evaluation of his or her life. A typical survey question is "All things considered, how satisfied are you with your life as a whole nowadays?" with answers given on a scale ranging from "extremely dissatisfied" to "extremely satisfied". Another commonly used question, the Cantril Ladder, asks respondents to rank their life between the worst and best possible life for them. Section II.3 describes the questions that are available in the surveys we analyze.

SWL provides a measure of individual welfare that includes all the things a person cares about with the importance he or she assigns to them. The first well-known economics paper using SWL data as a proxy for welfare or utility is probably Easterlin (1974). The rate of publications has substantially increased around 2005, with such papers as Luttmer (2005), Van Praag and Baarsma (2005), Di Tella and MacCulloch (2006), Frey et al. (2007), Clark et al. (2008), and Layard et al. (2008). Deaton (2010) advocates its use in measuring international differences in poverty.

The use of SWL data raises two important concerns: interpersonal comparability and the linearity of the transformation between true utility and reported 
SWL. To appreciate these concerns, let $h_{j}$ denote the reported SWL of person $j$, and let $u_{j}$ denote her actual SWL or welfare. The interpersonal comparability problem is that different people could potentially use different transformations to report their utility: $h_{j}=f_{j}\left(u_{j}\right)$ and $h_{k}=f_{k}\left(u_{k}\right)$ with $f_{j} \neq f_{k}$. The linearity problem is that OLS regressions with $h_{j}$ as the dependent variable necessarily assume that equal differences in reported SWL correspond to equal differences in actual SWL, but that is only true if the reporting functions are linear.

There are three answers to these concerns. First, far from being a new and questionable requirement of SWL studies, interpersonal comparisons of wellbeing are a normal and unavoidable assumption in everyday life. As Harsanyi (1955) writes, "There is no doubt about the fact that people do make, or at least attempt to make, interpersonal comparisons of utility, both in the sense of comparing different persons' total satisfaction and in the sense of comparing increments and decrements in different persons' satisfaction." Second, research shows that SWL reports correlate as expected with other people's estimates, with neuropsychological measures, and with external factors that are expected to affect utility, and that they are in turn a good predictor of decisions, such as quitting and marital break-up (Clark et al., 2008). Finally, national differences in SWL are uncorrelated with ratings of hypothetical situations, implying that SWL ratings do not merely reflect cultural differences in how people rate their experiences (Bolle \& Kemp, 2009).

In common with other SWL research, we take interpersonal comparability for granted. Most importantly, we assume that any individual differences in SWL reporting are uncorrelated with regressors: there is no systematic tendency for people in high inequality countries to report their SWL differently than people in low inequality countries. Most of the analysis assumes linearity: equal differences in reported SWL correspond to equal differences in actual SWL. Relaxing linearity requires strong distributional assumptions (Clark et al., 2008; Layard et al., 2008). Nevertheless, as a robustness check we test a non-linear model (Section III.4.3) and an ordinal measure of SWL dispersion (Section III.4.4).

\section{II.2 Measuring inequality}

We use the standard deviation of SWL as our primary indicator of SWL dispersion, and the Gini coefficient of income for income inequality. One of the key properties of the Gini coefficient is scale invariance: changing the units 
(or currency) in which income is measured makes no difference to the Gini coefficient. This is an important property, since it is difficult to ensure that income is measured in comparable units across clusters.

SWL is reported on the same scale in different countries, making scaleinvariance irrelevant. The key property in a measure of SWL dispersion is invariance to additive shifts. Consider two clusters in which the distribution of SWL is the same except for an additive shift, so that the mean is higher in one cluster than in the other. We want our measure of dispersion to be the same in both clusters. This is the case for the variance or standard deviation, but not for the Gini coefficient or the coefficient of variation. ${ }^{9}$ The choice between the standard deviation and the variance makes little practical difference. We follow the precedent in this literature (Veenhoven, 1990; Kalmijn \& Veenhoven, 2005), and measure SWL dispersion by the standard deviation of the distribution. In Appendix A we include results using the variation ratio, which is defined as the proportion of observations not equal to the mode. The variation ratio is a more noisy measure of dispersion than the standard deviation, but as a purely ordinal measure of dispersion it provides an important robustness test.

\section{II.3 SWL surveys}

We use data from four surveys: the World Values Survey (WVS), the European Social Survey (ESS), the Gallup World Poll (GWP), and the GallupHealthways Well-Being Index (GHWBI). Table 1 summarizes key statistics about these surveys. The sections below provide more details.

\section{European Social Survey}

The European Social Survey ${ }^{10}$ includes 36 European countries and Israel. We use waves 1-7 with data from 2006 to 2015 with a total of 303,385 individual SWL observations. The SWL variable is life satisfaction (stflife), which is recorded on a $0-10$ scale, with end points labelled Extremely dissatisfied and Extremely satisfied. Clusters are defined by the combination of country (cntry) and wave (essround). The interview year (inwyye, inwyr, inwyys,

\footnotetext{
${ }^{9}$ These last two measures are reduced by a positive additive shift. Using these measures would therefore result in a mechanical negative correlation between happiness and inequality even if the reporting scale is unbounded!

${ }^{10} \mathrm{http}$ ://www.europeansocialsurvey.org
} 
Table 1: The SWL surveys used in the paper.

\begin{tabular}{|c|c|c|c|c|}
\hline & $\operatorname{ESS}^{a}$ & $\mathrm{WVS}^{a}$ & $\mathrm{GWP}^{a}$ & $\mathrm{GHWBI}^{a}$ \\
\hline Year range & $2002-2015$ & 1989-2014 & 2006-2014 & $2008-2011$ \\
\hline Geographic Units & countries & countries & countries & states \\
\hline No. geog. units & 36 & 93 & 164 & 50 \\
\hline No. clusters & 166 & 222 & 1,120 & 200 \\
\hline Individual obs. & 303,853 & 314,903 & $1,341,049$ & $1,404,982$ \\
\hline SWL variable & $\begin{array}{l}\text { Satisfaction } \\
\text { with life }\end{array}$ & $\begin{array}{c}\text { Satisfaction } \\
\text { with life }\end{array}$ & $\begin{array}{l}\text { Cantril } \\
\text { Ladder }\end{array}$ & $\begin{array}{l}\text { Cantril } \\
\text { Ladder }\end{array}$ \\
\hline SWL range & $0-10$ & $1-10$ & $0-10$ & $0-10$ \\
\hline Mean SWL ${ }^{b}$ & $\begin{array}{c}4.22-8.58 \\
6.85 \pm 0.96\end{array}$ & $\begin{array}{c}3.94-8.49 \\
6.58 \pm 1.05\end{array}$ & $\begin{array}{c}2.69-8.02 \\
5.45 \pm 1.11\end{array}$ & $\begin{array}{c}6.28-7.48 \\
6.81 \pm 0.19\end{array}$ \\
\hline SWL inequality $^{b}$ & $\begin{array}{c}1.39-3.08 \\
2.10 \pm 0.36\end{array}$ & $\begin{array}{c}1.33-3.00 \\
2.19 \pm 0.33\end{array}$ & $\begin{array}{c}0.86-3.22 \\
1.94 \pm 0.32\end{array}$ & $\begin{array}{c}1.68-2.39 \\
2.03 \pm 0.10\end{array}$ \\
\hline Income inequality $^{b}$ & $\begin{array}{c}0.24-0.43 \\
0.32 \pm 0.04\end{array}$ & $\begin{array}{c}0.17-0.65 \\
0.39 \pm 0.10\end{array}$ & $\begin{array}{c}0.17-0.65 \\
0.38 \pm 0.08\end{array}$ & $\begin{array}{c}0.40-0.50 \\
0.46 \pm 0.02\end{array}$ \\
\hline $\log \mathrm{GDP}^{b}$ & $\begin{array}{c}8.89-11.40 \\
10.35 \pm 0.45\end{array}$ & $\begin{array}{l}6.75-11.75 \\
9.36 \pm 0.97\end{array}$ & $\begin{array}{l}6.42-11.81 \\
9.27 \pm 1.17\end{array}$ & $\begin{array}{l}10.24-11.06 \\
10.60 \pm 0.16\end{array}$ \\
\hline Social trust ${ }^{c}$ & Yes & Yes & Partial & \\
\hline View of inequality ${ }^{c}$ & Yes & Yes & & \\
\hline Emotions yesterday $^{c}$ & & & Yes & \\
\hline
\end{tabular}

${ }^{a}$ Section II.3 explains these acronyms.

${ }^{b}$ The columns report for each of the surveys the overall range, mean, and standard deviation of the variable in that row. The row variables correspond to $\mu_{i}, \sigma_{i}, g_{i}$, and $Y_{i}$ in the regression equations.

${ }^{c}$ Columns report whether the survey has the information in the row. 
and supqyr) is used for matching with macro variables. Personal controls include gender (gndr), age (age and agea), education (edulvla and eisced values recoded into the edulvla range), marital status (marital, marsts, maritala, and maritalb), and unemployment (unemp3m and unempla). We use poststratification weights (pspwght) for weighting, except in wave 7 when only design weights (dweight) are available. We use the variable gincdif as measuring a preference for equality. Subjects were asked to record their agreement or disagreement with the following statement: "The government should take measures to reduce differences in income levels". Answers were originally on a 5 point scale ranging from Agree strongly to Disagree strongly, which we invert to $\mathrm{a}-2$ to +2 range, with +2 denoting strong agreement. The trust variable ppltrst is a $0-10$ variable with endpoints labelled You can't be too careful and Most people can be trusted.

\section{World Values Survey}

The World Values Survey includes data from 98 countries. We use waves 1-6 with data from 1981 to 2014 with a total of 314,903 individual SWL observations. ${ }^{11}$ The SWL variable we use is life satisfaction (A170) reported on a 1-10 scale with endpoints labelled Dissatisfied and Satisfied. Clusters are defined by the combination of country (S003) and wave (S002). The interview year (S020) is used for matching with macro variables. Personal controls include gender (X001), age (X003), education (X025) and marital status (X007). Weights are given by S017. The variable E035 codes a preference for equality. Subjects were asked to report their view on a 1 to 10 scale with 1 labelled "Incomes should be made more equal" and 10 labelled "We need larger income differences as incentives for individual effort". We inverted this scale, so that higher values denote a preference for equality. Finally, the trust variable A165 is a binary question, asking people whether "Most people can be trusted" or "you can't be too careful". We recode it so that a positive value denotes agreement with "Most people can be trusted".

\footnotetext{
${ }^{11} \mathrm{http}: / /$ www.worldvaluessurvey.org. We exclude data from Egypt in 2001 and from India in 2001 and 2006, as these particular surveys did not use the full SWL range.
} 


\section{Gallup World Poll}

The Gallup World Poll ${ }^{12}$ includes data from over 160 countries. We used the December 2014 version of the dataset, which includes data for every year from 2008 to 2014, and about 1.34 million individual observations. The SWL variable is the Cantril Ladder of Life (WP16) recorded on a 0-10 scale with end points labelled "Worst possible life for you" and "Best possible life for you". Clusters are defined by the combination of country code (ccode) and the interview year (YEAR_CALENDAR). Personal controls include gender (WP1219), age (WP1220), and marital status (WP1223). We use wgt for weighting observations. As in the World Values Survey, the trust variable WP9039 is binary, asking whether "most people can be trusted" or "you have to be careful in dealing with people". We recoded answers so that a positive value denotes agreement with "most people can be trusted". The emotions data we use includes the following variables: WP60 (well-rested), WP67 (enjoyment), WP69 (worry), WP70 (sadness), WP71 (stress), WP74 (anger), and WP6878 (happiness). These are all binary questions, asking whether the respondent experienced that particular emotion in the previous 24 hours.

\section{Gallup-Healthways Well-Being Index}

The Gallup-Healthways Well-Being Index ${ }^{13}$ includes data from the United States with enough observations for useful statistics at the state level. We use the May 2012 version of the dataset, which includes data for every year from 2008 to 2011 and a total of 1.4 million individual SWL observations. The subjective well-being variable is the Cantril Ladder of Life recorded on a $0-10$ scale. Clusters are defined by the combination of state (zipstate) and the interview year (obtained from the interview date, int_date). Personal controls include gender (sc7), age (age), marital status (wp1223) and education (d4). We use weight for weighting observations.

\section{II.4 Macro data}

We use the World Bank's World Development Indicators ${ }^{14}$ as our primary source for GDP per capita and income inequality data in different countries.

\footnotetext{
${ }^{12} \mathrm{http}: / /$ www.gallup.com/services/170945/world-poll.aspx

${ }^{13} \mathrm{http}: / /$ www.well-beingindex.com

${ }^{14} \mathrm{http}$ //data.worldbank.org/data-catalog/world-development-indicators
} 
GDP per capita is in constant prices adjusted for purchasing power parity. Income inequality is measured by the Gini coefficient of income. When data are missing, we interpolate linearly using the nearest data points when we have both more recent and older data, and use the most recent data available when we only have older data. At the opposite end, the World Bank data we use starts at 1990, and some World Values Survey observations are for earlier years. We use GDP data from version 8.1 of the Penn World Tables to fill in the missing years. ${ }^{15}$ For the Gallup-Healthways Well-Being Index we need US state level information. We use the U.S. Census Bureau's American Community Survey for Gini coefficients, and the Bureau of Economic Analysis for GDP. ${ }^{16}$

We use GDP per capita as an income control, since it is available in comparable form for all surveys. We have used household income data from the European Social Survey (ESS) and Gallup World Poll (GWP) for robustness checks against the possibility that the use of aggregate income might bias upwards our estimate of the effects of SWL inequality on average SWL. In the ESS sample our estimates of the effects of SWL inequality are actually higher using logs of household incomes, national means of the logs of household incomes, or logs of the national means of household incomes than they are using $\log$ GDP. The GWP results are more mixed, but for both surveys the sign and significance of the coefficients on SWL inequality as well as the results comparing SWL inequality and income inequality reported below are unchanged by using any of the alternative income measures.

\section{ANALYSIS}

Section III.1 discusses some general issues common to all our regressions. Section III.2 describes the baseline regressions that establish the partial correlation between SWL levels and SWL dispersion. Section III.3 describes the comparison with income inequality. Finally, Section III.4 describes the tests for whether the correlation between SWL levels and dispersion is real.

\footnotetext{
${ }^{15} \mathrm{https}: / /$ pwt.sas.upenn.edu. We use data from the earliest year in which we have GDP data from both sources (1990 for most countries) to normalize the Penn data that we use for years prior to 1990. This corrects for differences in the GDP, purchasing power, and population figures that the two datasets use, as well as for the across-the-board difference in the base year.

${ }^{16} \mathrm{https}: / /$ www.census.gov/programs-surveys/acs and http://www.bea.gov.
} 


\section{III.1 Considerations common to all regressions}

Previous work on the relationship between SWL levels and SWL dispersion has used cluster level regressions, with one observation per cluster (Delhey, 2004; Ott, 2005; Bolle et al., 2009; Quick, 2015). Our data has individual level observations, however, including (in two of the surveys) information about the individual's own attitude towards inequality. In order to take advantage of this information, we estimate individual level regressions with standard errors corrected for clustering. SWL inequality, income inequality, and log GDP per capita are measured in clusters defined by the combination of geographic unit (country or state) and time (survey wave or year). Observations with ambiguous values ("no answer", "don’t know") are treated as missing.

\section{III.2 Baseline correlations in different surveys}

Our baseline regression tests whether the correlations found in previous research (Delhey, 2004; Ott, 2005; Bolle et al., 2009) remain when we control for GDP per capita, as well as personal and region controls:

$$
h_{i j}=\alpha+\beta_{\sigma} \sigma_{i}+\beta_{Y} Y_{i}+\sum_{k} \gamma_{k} x_{i j k}+\epsilon_{i j},
$$

where $h_{i j}$ denotes the reported SWL of person $j$ in cluster $i, \sigma_{i}$ denotes the standard deviation of SWL in this cluster, $Y_{i}$ is the logarithm of GDP per capita in PPP terms, and $x_{i j k}$ are personal controls for gender, age, education, employment, and marital status. In the World Values Survey and Gallup World Poll we also add region dummies in order to control for between-region differences in SWL levels. ${ }^{17}$ Given previous research, the expectation is that $\beta_{\sigma}$ is negative. We also estimate a regression with geographic unit (country or state) dummies. This regression controls for any fixed differences in SWL levels between countries (including any fixed reporting biases), testing whether changes in SWL levels are correlated with changes in SWL dispersion.

\section{III.3 Comparing income inequality with SWL dispersion}

If SWL dispersion is a comprehensive measure of inequality, its correlation with individual well-being should be better identified than the corresponding

\footnotetext{
${ }^{17}$ Regions include: (i) the West (Europe, North America, and Oceania), (ii) Latin America, (iii) Asia, (iv) Middle East and North Africa, and (v) Sub-Saharan Africa.
} 
correlation for income inequality, or other less general measures of inequality. We estimate a variation of Equation 1 with the Gini coefficient of income, $g_{i}$ replacing $\sigma_{i}$ :

$$
h_{i j}=\alpha+\beta_{g} g_{i}+\beta_{Y} Y_{i}+\sum_{k} \gamma_{k} x_{i j k}+\epsilon_{i j},
$$

and a combined regression with both measures of inequality:

$$
h_{i j}=\alpha+\beta_{\sigma} \sigma_{i}+\beta_{g} g_{i}+\beta_{Y} Y_{i}+\sum_{k} \gamma_{k} x_{i j k}+\epsilon_{i j} .
$$

The hypotheses in Equation 3 are that the correlation with $\sigma_{i}$ remains significant: $\beta_{\sigma}<0$, and is larger in magnitude than the corresponding correlation with income inequality: $\left|\beta_{\sigma}\right|>\left|\beta_{g}\right|$.

\section{III.4 Testing for a mechanical correlation bias}

\section{III.4.1 Is the correlation stronger in subjects who care more about in- equality?}

Our first test exploits information about the degree to which different people care about income inequality, and by extension the degree to which they care about inequality in general. The World Values Survey and the European Social Survey ask respondents whether income differences should be reduced, with answers on a 5 level scale. The distribution of responses is far from uniform, with about three quarters of responders either agreeing or strongly agreeing with this statement. Nevertheless, there is enough variation for a useful indicator of how much a given responder cares about income inequality.

We estimate the following equation, where $e_{i j}$ denotes person's $i$ level of agreement that inequality should be reduced:

$$
h_{i j}=\alpha+\beta_{\sigma} \sigma_{i}+\beta_{g} g_{i}+\beta_{e} e_{i j}+\beta_{e \sigma} e_{i j} \sigma_{i}+\beta_{e g} e_{i j} g_{i+} \beta_{Y} Y_{i}+\sum_{k} \gamma_{k} x_{i j k}+\epsilon_{i j} .
$$

Our interest is in the interaction term $\beta_{e \sigma}$. If the correlation between SWL levels and dispersion is real, and if attitudes towards income inequality are strongly correlated with attitudes towards inequality in general, we would expect $\beta_{e \sigma}$ to be negative (stronger correlation among responders who care more about inequality). If, however, the correlation is primarily a mechanical artifact of the way SWL is reported, $\beta_{e \sigma}$ should be insignificantly different from zero. 


\section{III.4.2 Partialling out the mechanical effect of mean SWL}

Several of the datasets we use include measures of such SWL determinants as social trust and various emotions that are known to be correlated with the level of inequality. If SWL dispersion is a good measure of inequality, we would expect these variables to be correlated with SWL dispersion, and we would not expect this correlation to change significantly if we add SWL levels as a control. If, however, the correlation between SWL levels and SWL dispersion is mechanical, these variables should only be correlated with SWL dispersion through their correlation with SWL levels. In that case we would expect this correlation to be relatively small, and to disappear entirely if SWL levels are added as a control.

For a well-being determinant $w_{i j}$ we estimate the following two regressions:

$$
w_{i j}=\alpha+\beta_{\sigma} \sigma_{i}+\beta_{Y} Y_{i}+\sum_{k} \gamma_{k} x_{i j k}+\epsilon_{i j}
$$

and

$$
w_{i j}=\alpha^{\prime}+\beta_{\mu} \mu_{i}+\beta_{\sigma}^{\prime} \sigma_{i}+\beta_{Y}^{\prime} Y_{i}+\sum_{k} \gamma_{k}^{\prime} x_{i j k}+\epsilon_{i j}^{\prime},
$$

where $\mu_{i}$ denotes the mean SWL level in cluster $i$. If SWL dispersion is a good measure of inequality, we would expect $\beta_{\sigma}$ in Equation 5 to be negative. Since $\mu_{i}$ is positively correlated with $w_{i j}$, we should not be surprised if the correlation is weakened when $\mu_{i}$ is added to the regression (Equation 6), but it should remain negative:

$$
\beta_{\sigma} \leq \beta_{\sigma}^{\prime}<0 .
$$

Suppose, instead, that SWL dispersion has nothing to do with inequality, so that the correlation between SWL levels and SWL dispersion is purely mechanical (Figure 1). If that were the case, any correlation between $w_{i j}$ and $\sigma_{i}$ would be mediated by $\mu_{i}$, and should largely disappear when $\mu_{i}$ is added as a control in Equation 6: ${ }^{18}$

$$
\beta_{\sigma}<\beta_{\sigma}^{\prime} \approx 0 \text {. }
$$

The first well-being determinant we test is social trust. Survey questions on social trust have been validated by correlating answers with cross-country differences in the frequency with which experimentally dropped wallets were

\footnotetext{
${ }^{18}$ If the mechanical component of the correlation is a linear function of $\mu_{i}$ it should disappear entirely by the Frisch-Waugh-Lovell theorem.
} 
returned (Knack \& Keefer, 1997). Responses are available as a 0-10 numeric variable in the European Social Survey (ESS), and as a binary variable in the World Values Survey (WVS) and Gallup World Poll (GWP). There is no trust question in the Gallup-Healthways Well-Being Index. In ESS we estimate linear regressions, and in WVS and GWP we estimate a logit regression.

The other well-being determinants we use are yes/no questions on worry and stress in the previous day, and a question on whether the respondent fears walking alone. These questions are only available in the Gallup World Poll. As these are yes/no questions we use logit regressions. Since they are negatively related to well-being, they are predicted to increase in SWL inequality. The hypotheses in Equations 7 and 8 are therefore reversed, and $\beta_{\sigma}$ and $\beta_{\sigma}^{\prime}$ are predicted to be positive.

\section{III.4.3 Modelling the SWL reporting function}

Actual SWL may best be thought of as a continuous variable, but SWL reports are restricted to integers in a bounded range, such as $0-10$. As we note in the introduction and in Figure 1, the censoring and quantization could, in principle, create a mechanical correlation between SWL levels and SWL dispersion that has nothing to do with the level of inequality. Our approach in this section is to model the reporting function and reestimate the regressions of Section III.2 in actual SWL space.

This approach necessitates identifying assumptions on the distribution of actual SWL. Since our goal is to estimate a bound on the portion of the correlation between SWL levels and SWL dispersion that is mechanical, we assume that the distribution of actual SWL is symmetric. As the distribution of reported SWL is left-skewed, this assumption implies that the right tail of the distribution is censored, resulting in mechanical correlation between SWL levels and SWL dispersion. If, instead, the distribution of actual SWL is as left-skewed as the distribution of reported SWL, there would be little or no censoring, and little or no mechanical correlation. The symmetric distribution assumption can thus be seen as providing an upper bound on the likely mechanical correlation effect.

The two commonly used symmetric distributions are the normal and logistic distributions. We chose the logistic distribution as it fits the data better. We use maximum likelihood to estimate the mean $\mu_{i}^{*}$ and standard deviation $\sigma_{i}^{*}$ in 
each cluster $i$. We then estimate an analogue of Equation 1,

$$
\bar{h}_{i j}^{*}=\alpha^{*}+\beta_{\sigma}^{*} \sigma_{i}^{*}+\beta_{Y}^{*} Y_{i}+\sum_{k} \gamma_{k}^{*} x_{i j k}+\epsilon_{i j}^{*},
$$

where $\bar{h}_{i j}^{*}$ is the expected value in the distribution of actual SWL values that are consistent with the SWL report $h_{i j}$.

The coefficient $\beta_{\sigma}^{*}$ in Equation 9 can then be compared with the corresponding coefficient $\beta_{\sigma}$ in Equation 1. If actual SWL is negatively correlated with inequality, $\beta_{\sigma}^{*}$ should be negative. If, however, $\beta_{\sigma}$ is only negative because of the non-linearity in the reporting function, we would expect $\beta_{\sigma}^{*}$ to be zero. If the correlation is partly real and partly mechanical, we may expect $\beta_{\sigma}^{*}$ to be negative, but smaller in magnitude than $\beta_{\sigma}$.

The estimates of the mechanical correlation component that are obtained using this method are driven by the difference between the distribution of reported SWL and our assumptions on the distribution of actual SWL. The distribution of reported SWL in most countries is left skewed. In a typical country, the mode may be at 7 on a $0-10$ scale, with a large majority of respondents reporting a value of 6 or above, but some respondents reporting values as low as 0 or 1 . Our assumption that actual SWL is symmetrically distributed explains this left skew as the result of non-linearities in the reporting function. There are, however, good reasons to expect the distribution of actual SWL to be left skewed. In particular, common mental health problems such as anxiety and depression can cause people to be far less happy with their lives, adding a left skew to what might otherwise be an approximately symmetric distribution. The absence of satiation in SWL regressions also argues against non-linearities in the reporting function (Stevenson \& Wolfers, 2013). We should thus expect this estimation procedure to overestimate the mechanical component of the correlation between SWL and inequality, or equivalently, to underestimate the true correlation that we are interested in.

\section{III.4.4 Ordinal measure of SWL dispersion}

Finally, we repeat the regressions of Sections III.2, III.3 and III.4.1 using the variation ratio measure of SWL dispersion (Section II.2). 


\section{RESULTS}

Section IV.1 reports the results of all satisfaction with life regressions: the baseline regressions (Section III.1), the corresponding regressions with income inequality (Section III.3), and the regressions testing whether the correlation between the mean and dispersion of the SWL distribution is stronger among those responders who describe themselves as more concerned with inequality (Section III.4.1). Section IV.2 turns to regressions of SWL components in which we partial out the effect of mean SWL (Section III.4.2). Section IV.3 describes the results of modelling the SWL reporting function to estimate the correlation between the mean and dispersion of the SWL distribution in actual SWL space (Section III.4.3). Appendix A reports results with the variation measure of SWL dispersion.

\section{IV.1 Satisfaction with life regressions}

The results of the regressions are qualitatively similar in all four surveys: SWL dispersion is strongly negatively correlated with SWL despite the inclusion of GDP per capita and other controls; the corresponding correlation with income inequality is consistently weaker; the correlation is stronger among those particularly concerned with inequality, consistent with the hypothesis that this correlation is not mechanical, but real, capturing the true correlation between SWL and comprehensive inequality. The following sections describe the results for each survey in turn.

\section{European Social Survey}

The results for the European Social Survey are in Table 2. The partial correlation between SWL levels and SWL dispersion is negative: $\hat{\beta}_{\sigma}=-0.21$ and is strongly statistically significant $(p \ll 0.001)$. The corresponding correlation with the Gini coefficient of income (Column 2 ) is also statistically significant $(p<0.001)$, but the standardized beta coefficient is only a third in size: $\hat{\beta}_{g}=-0.07$ as compared with $\hat{\beta}_{\sigma}=-0.21$. When both measures of inequality are included in the same regression (Column 3), the Gini coefficient drops to insignificance, whereas the coefficient on SWL dispersion is hardly changed: $\hat{\beta}_{\sigma}=-0.20$. Column 4 adds the subjective importance of reducing inequality and its interaction with SWL and income inequality. As expected, the inter-

action term with SWL dispersion is negative: $\hat{\beta}_{e \sigma}=-0.22(p<0.001)$, but 
the interaction term with income inequality is insignificant and of the wrong sign. The interaction term with SWL dispersion remains negative even when country dummies are included (Column 5). In summary, the correlation between SWL levels and SWL dispersion is consistently negative in both the cross-section and across time, is more negative than the correlation between SWL levels and income inequality, and is stronger among those who describe themselves as particularly averse to inequality.

\section{World Values Survey}

The results for the World Value Survey (Table 3) are not as strong, but are otherwise similar to the European Social Survey results. The partial correlation with SWL dispersion is $\hat{\beta}_{\sigma}=-0.17(p \ll 0.001)$. The corresponding correlation with income inequality (Column 2$)$ is also negative $\left(\hat{\beta}_{g}=-0.05\right)$, but is not statistically significant $(p<0.268)$. When both forms of inequality are included in the same regression (Column 3), the coefficient on SWL dispersion is virtually unchanged: $\hat{\beta}_{\sigma}=-0.17$ and the coefficient on income inequality remains insignificant. The interaction term with the importance of SWL dispersion (Column 4) is negative: $\hat{\beta}_{e \sigma}=-0.17(p<0.001)$, and this remains the case when country dummies are added (Column 6$)$ with $\hat{\beta}_{e \sigma}=-0.13$ $(p<0.001)$.

\section{Gallup World Poll}

The correlations in the Gallup World Poll (Table 4) are mostly similar to those of the previous two surveys, though income inequality is more significant than in the other two surveys. The partial correlation between SWL levels with SWL dispersion is $\hat{\beta}_{\sigma}=-0.10(p \ll 0.001)$. The corresponding correlation with income inequality (Column 2 ) is also statistically significant, but weaker: $\hat{\beta}_{g}=-0.06$. When both inequality measures are included in the same regression (Column 3), $\hat{\beta}_{g}$ drops in magnitude to $-0.04(p<0.006)$, while $\hat{\beta}_{\sigma}$ is unchanged: $\hat{\beta}_{\sigma}=-0.10(p<0.001)$. When country dummies are added (Column 4$) \hat{\beta}_{\sigma}$ drops to -0.05 but remains strongly statistically significant $(p<0.001)$. Interestingly, the coefficient on income inequality becomes stronger: $\hat{\beta}_{g}=-0.09$. 
Table 2: SWL and inequality regressions in the European Social Survey with the standard deviation measure of SWL dispersion ${ }^{a}$

\begin{tabular}{|c|c|c|c|c|c|}
\hline & \multicolumn{5}{|c|}{ Dependent variable: life satisfaction $(0-10)$} \\
\hline & (1) & (2) & (3) & (4) & $(5)$ \\
\hline $\begin{array}{l}\text { SWL } \\
\text { standard deviation }^{b}\end{array}$ & $\begin{array}{l}-0.21^{* * *} \\
(-9.82)\end{array}$ & & $\begin{array}{l}-0.20^{* * *} \\
(-8.77)\end{array}$ & $\begin{array}{l}-0.16^{* * *} \\
(-8.00)\end{array}$ & $\begin{array}{l}-0.11^{* * *} \\
(-4.35)\end{array}$ \\
\hline $\begin{array}{l}\text { Income } \\
\text { Gini coef. } b\end{array}$ & & $\begin{array}{l}-0.07^{* *} \\
(-3.33)\end{array}$ & $\begin{array}{c}-0.02 \\
(-0.85)\end{array}$ & $\begin{array}{l}-0.02 \\
(-1.17)\end{array}$ & $\begin{array}{l}-0.04^{*} \\
(-2.13)\end{array}$ \\
\hline $\begin{array}{l}\text { GDP per capita } \\
\text { in } \log \text { terms } b\end{array}$ & $\begin{array}{l}0.18^{* * *} \\
(9.30)\end{array}$ & $\begin{array}{l}0.33^{* * *} \\
(19.21)\end{array}$ & $\begin{array}{l}0.18^{* * *} \\
(9.27)\end{array}$ & $\begin{array}{l}0.17^{* * *} \\
(8.42)\end{array}$ & $\begin{array}{c}0.29 * * * \\
(4.63)\end{array}$ \\
\hline $\begin{array}{l}\text { Thinks inequality } \\
\text { is too } \operatorname{high}^{c}\end{array}$ & & & & $\begin{array}{c}0.08 \\
(1.29)\end{array}$ & $\begin{array}{l}0.09^{* *} \\
(2.75)\end{array}$ \\
\hline$\times \begin{array}{l}\text { SWL } \\
\text { standard deviation }\end{array}$ & & & & $\begin{array}{c}-0.22^{* * *} \\
(-4.73)\end{array}$ & $\begin{array}{l}-0.23^{* * *} \\
(-9.19)\end{array}$ \\
\hline $\begin{array}{l}\text { Income } \\
\times \text { Gini coef. }\end{array}$ & & & $(0.93)$ & $\begin{array}{c}0.05 \\
(1.39)\end{array}$ & 0.06 \\
\hline Country dummies & & & & & Yes \\
\hline No. of observations & 303853 & 301960 & 301960 & 301960 & 301960 \\
\hline $\begin{array}{l}{ }^{a} \text { Standardised beta coeffici } \\
\text { Statistical significance ind } \\
\text { Clusters defined by countr } \\
{ }^{b} \text { Cluster level variables: } \sigma_{i} \text {, } \\
{ }^{c} 5 \text { level variable indicating } \\
\text { values indicate agreement } \\
{ }^{d} \text { Gender age age sauared }\end{array}$ & $\begin{array}{l}\text { nts; } t \text { statisti } \\
\text { cators: }{ }^{*} p< \\
\text { /wave coml } \\
g_{i} \text {, and } Y_{i} \text { in } \\
\text { ndividual } \mathrm{p} \\
\text { ind negative }\end{array}$ & $\begin{array}{l}\text { S corrected } \\
0.05,{ }^{* *} p< \\
\text { nation. } \\
\text { he text. } \\
\text { ference for } \\
\text { values disa }\end{array}$ & equality $\left(e_{i j}\right.$ & the text). & ositive \\
\hline
\end{tabular}


Table 3: SWL and inequality regressions in the World Values Survey with the standard deviation measure of SWL dispersion ${ }^{a}$

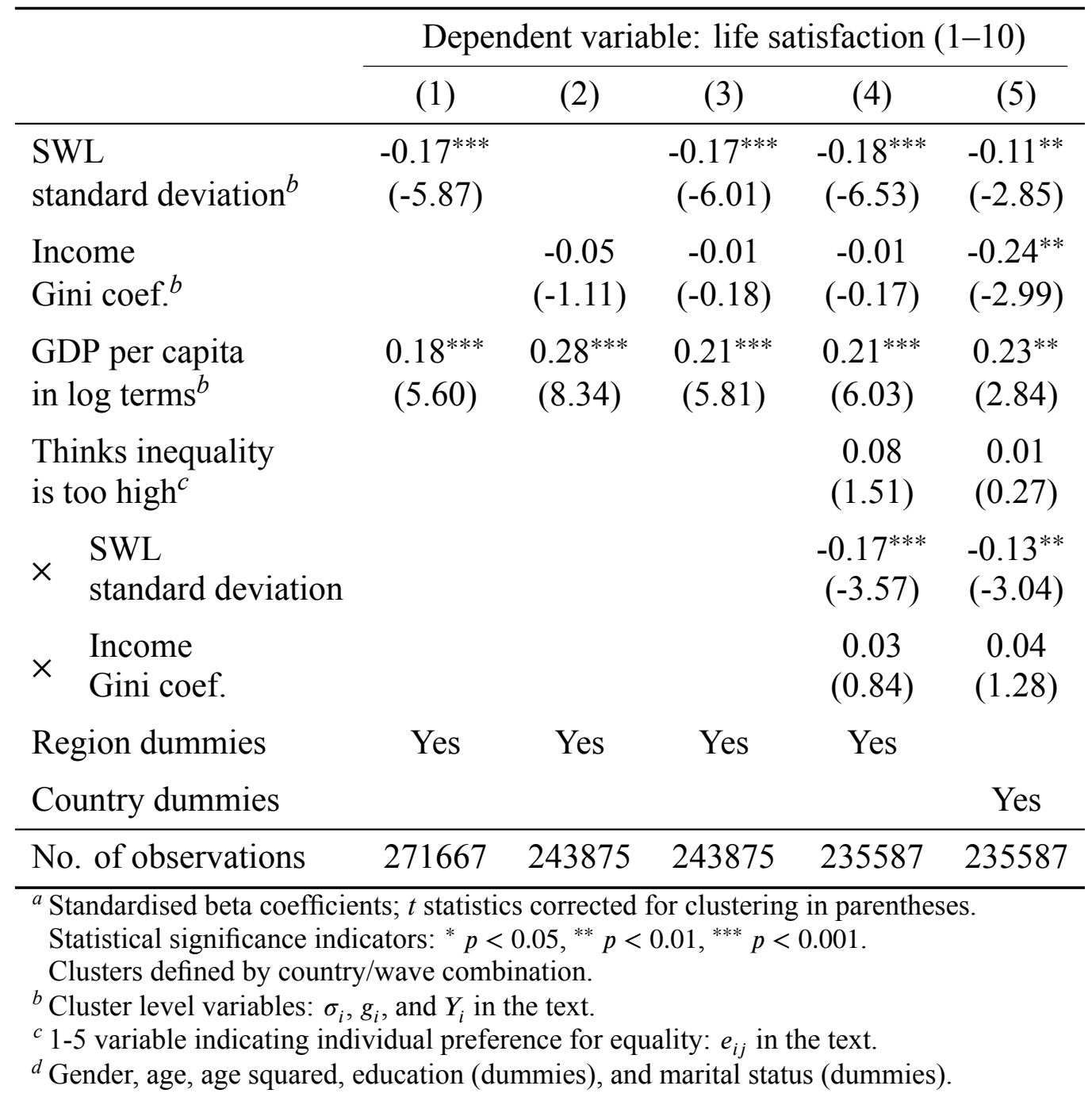


Table 4: SWL and inequality regressions in the Gallup World Poll with the standard deviation measure of SWL dispersion ${ }^{a}$

\begin{tabular}{|c|c|c|c|c|}
\hline & \multicolumn{4}{|c|}{ Dependent variable: Cantril ladder $(0-10)$} \\
\hline & (1) & (2) & (3) & (4) \\
\hline $\begin{array}{l}\text { SWL } \\
\text { standard deviation }^{b}\end{array}$ & $\begin{array}{l}-0.10^{* * *} \\
(-9.49)\end{array}$ & & $\begin{array}{l}-0.10^{* * *} \\
(-8.81)\end{array}$ & $\begin{array}{l}-0.05^{* * *} \\
(-4.15)\end{array}$ \\
\hline $\begin{array}{l}\text { Income } \\
\text { Gini coef. } b\end{array}$ & & $\begin{array}{l}-0.06^{* * *} \\
(-3.72)\end{array}$ & $\begin{array}{l}-0.04^{* *} \\
(-2.76)\end{array}$ & $\begin{array}{l}-0.09^{* *} \\
(-3.03)\end{array}$ \\
\hline $\begin{array}{l}\text { GDP per capita } \\
\text { in } \log \text { terms } b\end{array}$ & $\begin{array}{l}0.38^{* * *} \\
(31.69)\end{array}$ & $\begin{array}{l}0.39 * * * \\
(26.33)\end{array}$ & $\begin{array}{l}0.39^{* * *} \\
(27.23)\end{array}$ & $\begin{array}{c}0.45^{* * *} \\
(4.87)\end{array}$ \\
\hline Region dummies & Yes & Yes & Yes & \\
\hline Country dummies & & & & Yes \\
\hline No. of observations & 1256817 & 1133621 & 1133621 & 1133621 \\
\hline
\end{tabular}


Table 5: SWL and inequality regressions in the Gallup-Healthways Well-Being Index with the standard deviation measure of SWL dispersion ${ }^{a}$

\begin{tabular}{|c|c|c|c|c|}
\hline & \multicolumn{4}{|c|}{ Dependent variable: Cantril ladder $(0-10)$} \\
\hline & (1) & (2) & (3) & (4) \\
\hline $\begin{array}{l}\text { SWL } \\
\text { standard deviation }^{b}\end{array}$ & $\begin{array}{l}-0.05^{* * *} \\
(-8.38)\end{array}$ & & $\begin{array}{l}-0.06^{* * *} \\
(-9.46)\end{array}$ & $\begin{array}{l}-0.13^{* * *} \\
(-29.22)\end{array}$ \\
\hline $\begin{array}{l}\text { Income } \\
\text { Gini coef. }\end{array}$ & & $\begin{array}{c}0.01 \\
(1.12)\end{array}$ & $\begin{array}{l}0.02^{* *} \\
(2.87)\end{array}$ & $\begin{array}{c}-0.01 \\
(-1.50)\end{array}$ \\
\hline $\begin{array}{l}\text { GDP per capita } \\
\text { in } \log \text { terms } b\end{array}$ & $\begin{array}{c}-0.00 \\
(-0.31)\end{array}$ & $\begin{array}{c}-0.00 \\
(-0.36)\end{array}$ & $\begin{array}{c}-0.00 \\
(-0.29)\end{array}$ & $\begin{array}{l}-0.02 \\
(-1.21)\end{array}$ \\
\hline State dummies & & & & Yes \\
\hline No. of observations & 1363274 & 1363274 & 1363274 & 1363274 \\
\hline
\end{tabular}

\section{Gallup-Healthways Well-Being Index}

Results in the Gallup-Healthways Well-Being Index (Table 5) are also qualitatively similar. The partial correlation with SWL dispersion is $\hat{\beta}_{\sigma}=-0.05$ ( $p \ll 0.001)$. Income inequality is not statistically significant (Column 2 ). When both forms of inequality are included (Column 3 ) the coefficient on SWL dispersion is unchanged: $\hat{\beta}_{\sigma}=-0.06$, while the coefficient on income inequality is statistically significant $(p<0.005)$ but with an unexpected positive sign $\left(\hat{\beta}_{g}=0.02\right)$. Adding state dummies (Column 4$)$ causes a sharp reduction in the coefficient on SWL dispersion: $\hat{\beta}_{\sigma}=-0.13$, but it remains strongly statistically significant.

\section{IV.2 Partialling out the mechanical effect of mean SWL}

This section reports the results of the partialling out analysis of Section III.4.2. The results for social trust are in Table 6 . The six columns are in pairs corre- 
sponding to the three surveys that include social trust questions: the European Social Survey (ESS), the World Values Survey (WVS), and the Gallup World Poll (GWP). Consistent with our hypotheses, social trust is strongly negatively correlated with SWL dispersion in all three surveys (Columns 1,3, and 5). Income inequality, by contrast, is borderline statistically significant in the ESS and WVS, and completely insignificant in the GWP. When mean SWL in the cluster is added to the equation (Columns 2, 4, and 6) the coefficient on SWL dispersion is completely unchanged in the WVS, and only marginally reduced in size in the other two surveys: from -0.25 to -0.21 in the ESS, and from -0.25 to -0.22 in the GWP. In all three cases the coefficient remains strongly significant ( $p<0.001$ in ESS and GWP, and $p<0.01$ in WVS). Table 7 reports the results for worry, stress, and fear of walking alone. As expected, SWL dispersion is positively correlated with worry, stress, and fear of walking alone (Columns 1,3 and 5). As with social trust (Table 6) the magnitude of the correlation remains strongly statistically significant $(p<0.001)$ when mean SWL is added to the regressions, and is barely changed in size (Columns 2, 4, and $6)$.

The results in this section are consistent: a small to non-existent change in the magnitude of the correlation with SWL dispersion with mean SWL is added to the regression. It follows that only a small component of the correlation is mediated by mean SWL, and that the bulk of the correlation captures the true correlation with comprehensive inequality, rather than any mechanical correlation effect.

\section{IV.3 Modelling the SWL reporting function}

Table 8 compares the results of the logistic distribution model of Section III.4.3 with the corresponding linear model. The distribution of SWL is a little wider in the logistic model in all the surveys, both across and within clusters (the latter resulting in a higher level of SWL dispersion). This result is consistent with some systematic distortion due to the censoring inherent in SWL reports. Consequently, it is not surprising that the regression coefficient on SWL dispersion is smaller in size in the logistic model, though it remains strongly statistically significant in all the surveys. The greatest decrease is in World Values

Survey, with the regression coefficient decreasing in size from $\hat{\beta}_{\sigma}=-0.17$ to $\hat{\beta}_{\sigma}^{*}=-0.10$.

These results suggest that up to a third of the correlation between SWL 
Table 6: Social trust and SWL dispersion regressions in the European Social Survey (ESS), the World Values Survey (WVS), and the Gallup World Poll (GWP). ${ }^{a}$

\begin{tabular}{|c|c|c|c|c|c|c|}
\hline & \multicolumn{6}{|c|}{ Dependent variable: social trust } \\
\hline & \multicolumn{2}{|l|}{ ESS } & \multicolumn{2}{|c|}{ WVS } & \multicolumn{2}{|c|}{ GWP } \\
\hline $\begin{array}{l}\text { Mean } \\
\text { SWL }^{b}\end{array}$ & & $\begin{array}{l}0.09^{* *} \\
(2.94)\end{array}$ & & $\begin{array}{c}0.01 \\
(0.10)\end{array}$ & & $\begin{array}{c}0.15 \\
(1.43)\end{array}$ \\
\hline $\begin{array}{l}\text { SWL } \\
\text { dispersion }^{b}\end{array}$ & $\begin{array}{l}-0.25^{* * *} \\
(-11.64)\end{array}$ & $\begin{array}{l}-0.21^{* * *} \\
(-7.73)\end{array}$ & $\begin{array}{l}-0.18^{* *} \\
(-3.24)\end{array}$ & $\begin{array}{l}-0.18^{* *} \\
(-2.62)\end{array}$ & $\begin{array}{l}-0.25^{* * *} \\
(-3.71)\end{array}$ & $\begin{array}{l}-0.22^{* *} \\
(-3.29)\end{array}$ \\
\hline $\begin{array}{l}\text { Income } \\
\text { inequality }\end{array}$ & $\begin{array}{c}-0.03 \\
(-1.88)\end{array}$ & $\begin{array}{c}-0.03 \\
(-1.97)\end{array}$ & $\begin{array}{c}-0.20^{*} \\
(-2.10)\end{array}$ & $\begin{array}{l}-0.20^{*} \\
(-2.09)\end{array}$ & $\begin{array}{l}-0.20^{*} \\
(-0.50)\end{array}$ & $\begin{array}{l}-0.20^{*} \\
(-0.32)\end{array}$ \\
\hline $\begin{array}{l}\text { Log GDP } \\
\text { per capita }\end{array}$ & $\begin{array}{l}0.07^{* * *} \\
(3.55)\end{array}$ & $\begin{array}{c}0.02 \\
(0.95)\end{array}$ & $\begin{array}{l}0.21^{* * *} \\
(3.96)\end{array}$ & $\begin{array}{c}0.21^{* *} \\
(3.03)\end{array}$ & $\begin{array}{c}0.29^{* *} \\
(3.17)\end{array}$ & $\begin{array}{c}0.18 \\
(1.38)\end{array}$ \\
\hline Observations & 30231 & & 2325 & & 17300 & \\
\hline
\end{tabular}


Table 7: Logit regressions relating worry, stress, and fear of walking alone to SWL dispersion in the Gallup World Poll. ${ }^{a}$

\begin{tabular}{|c|c|c|c|c|c|c|}
\hline \multirow{3}{*}{ Mean } & \multicolumn{6}{|c|}{ Dependent variable } \\
\hline & \multicolumn{2}{|c|}{ Worry } & \multicolumn{2}{|c|}{ Stress } & \multicolumn{2}{|c|}{ Fear } \\
\hline & \multicolumn{3}{|c|}{$\begin{array}{l}-0.19^{* * *} \\
(-7.06)\end{array}$} & $\begin{array}{c}0.01 \\
(0.14)\end{array}$ & \multicolumn{2}{|r|}{$\begin{array}{c}-0.20^{* *} \\
(6.00)\end{array}$} \\
\hline $\begin{array}{l}\text { SWL } \\
\text { dispersion }^{b}\end{array}$ & $\begin{array}{l}0.16^{* * *} \\
(-11.64)\end{array}$ & $\begin{array}{c}0.12^{* * *} \\
(-7.73)\end{array}$ & $\begin{array}{c}0.19^{* * *} \\
(-3.71)\end{array}$ & $\begin{array}{c}0.20^{* * *} \\
(-3.29)\end{array}$ & $\begin{array}{l}0.12^{* * *} \\
(-3.24)\end{array}$ & $\begin{array}{l}0.09^{* * *} \\
(-2.62)\end{array}$ \\
\hline $\begin{array}{l}\text { Log GDP } \\
\text { per capita }^{b}\end{array}$ & $\begin{array}{c}-0.04^{*} \\
(-2.15)\end{array}$ & $\begin{array}{l}0.10^{* * *} \\
(3.57)\end{array}$ & $\begin{array}{l}0.22^{* * *} \\
(9.98)\end{array}$ & $\begin{array}{l}0.22^{* * *} \\
(6.39)\end{array}$ & $\begin{array}{c}-0.11^{* *} \\
(3.16)\end{array}$ & $\begin{array}{r}0.03 \\
(-0.72)\end{array}$ \\
\hline Observations & \multicolumn{2}{|c|}{1189093} & \multicolumn{2}{|c|}{1092930} & \multicolumn{2}{|c|}{1102859} \\
\hline \multicolumn{7}{|c|}{$\begin{array}{l}{ }^{a} \text { Standardised beta coefficients; } t \text { statistics corrected for clustering in parentheses. } \\
\text { Statistical significance indicators: }{ }^{*} p<0.05,{ }^{* *} p<0.01,{ }^{* * *} p<0.001 . \\
\text { Clusters defined by country/wave combination. All regressions also include regional } \\
\text { dummies and personal controls (gender, age, age squared, education dummies, and } \\
\text { marital status dummies). } \\
{ }^{b} \text { Cluster level variables: } \mu_{i}, \sigma_{i} \text {, and } Y_{i} \text { in the text. }\end{array}$} \\
\hline
\end{tabular}


Table 8: Comparison of the logistic and linear models in the distribution of mean SWL in different clusters, SWL dispersion in those clusters, and the coefficient in a regression of SWL on SWL dispersion.

\begin{tabular}{|c|c|c|c|c|}
\hline & $\mathrm{ESS}^{a}$ & $\mathrm{WVS}^{a}$ & $\mathrm{GWP}^{a}$ & $\mathrm{GHWBI}^{a}$ \\
\hline \multicolumn{5}{|c|}{ Linear model } \\
\hline Mean $\mathrm{SWL}^{b}$ & $6.85 \pm 0.96$ & $6.58 \pm 1.05$ & $5.45 \pm 1.11$ & $6.81 \pm 0.19$ \\
\hline SWL dispersion $^{b}$ & $2.10 \pm 0.36$ & $2.19 \pm 0.33$ & $1.94 \pm 0.32$ & $2.03 \pm 0.10$ \\
\hline $\begin{array}{l}\text { Regression } \\
\text { coefficient }\left(\hat{\beta}_{\sigma}\right)^{c}\end{array}$ & $\begin{array}{c}-0.21^{* * *} \\
(-9.82)\end{array}$ & $\begin{array}{c}-0.17^{* * *} \\
(-5.87)\end{array}$ & $\begin{array}{c}-0.10^{* * *} \\
(-9.49)\end{array}$ & $\begin{array}{c}-0.05^{* * *} \\
(-8.38)\end{array}$ \\
\hline \multicolumn{5}{|c|}{ Logistic model } \\
\hline Mean $\mathrm{SWL}^{b}$ & $6.88 \pm 1.04$ & $6.71 \pm 1.19$ & $5.52 \pm 1.12$ & $6.99 \pm 0.18$ \\
\hline $\mathrm{SWL}_{\text {dispersion }} b$ & $2.24 \pm 0.43$ & $2.49 \pm 0.53$ & $2.00 \pm 0.42$ & $2.09 \pm 0.11$ \\
\hline $\begin{array}{l}\text { Regression } \\
\text { coefficient }\left(\hat{\beta}_{\sigma}\right)^{c}\end{array}$ & $\begin{array}{l}-0.15^{* * *} \\
(-5.25)\end{array}$ & $\begin{array}{l}-0.10^{* *} \\
(-3.01)\end{array}$ & $\begin{array}{c}-0.08^{* * *} \\
(-8.03)\end{array}$ & $\begin{array}{l}-0.03^{* * *} \\
(-5.36)\end{array}$ \\
\hline \multicolumn{5}{|c|}{$\begin{array}{l}a \text { Section II.3 explains these acronyms. } \\
b \text { The columns report for each of the surveys the mean and standard deviation of the } \\
\text { variable in that row. The row variables correspond to } \mu_{i} \text { and } \sigma_{i} \text { in the regression } \\
\text { equations. } \\
{ }^{c} \text { Standardised beta coefficients; } t \text { statistics corrected for clustering in parentheses. } \\
\text { Statistical significance indicators: }{ }^{*} p<0.05,{ }^{* *} p<0.01,{ }^{* * *} p<0.001 \text {. }\end{array}$} \\
\hline
\end{tabular}

and SWL dispersion may be an artifact of the reporting function. As argued in Section III.4.3, this estimate should be seen as an upper bound. It is entirely possible that the left skew observed in the distribution of reported SWL is also a feature of actual SWL. If that's the case, there may be no distortion in mean SWL, and no mechanical component to the observed correlation between SWL and SWL dispersion.

\section{DISCUSSION}

We set out in this paper to test the proposition that SWL dispersion offers a comprehensive measure of inequality - one that subsumes the many and var- 
ious component forms of inequality in particular domains. We started our investigation by replicating and extending previous findings that countries with high mean SWL tend to have a substantially lower SWL dispersion, showing that these correlations remain strong when controlling for GDP per capita, and are much better statistically identified than the corresponding correlations between SWL and income inequality. When both forms of inequality are included in the regression, the coefficient on SWL dispersion is little changed. These results all suggest that SWL dispersion adds to the information provided by income inequality in important ways.

While these results were encouraging, they do little to allay the concern that the correlation between the mean and standard deviation of the SWL distribution may be a mechanical artifact - higher SWL levels causing a censoring of the reported SWL distribution, and hence a lower dispersion. We employed three different tests to address this concern. In the first, we found that the correlation is substantially stronger among respondents who claim to be particularly concerned with inequality - as should be the case if the correlation is real, but not if it is merely a mechanical artifact. In the second, we examined the correlation between SWL dispersion and subjective well-being determinants such as social trust that are known to be correlated with inequality. We found that this correlation is large, and that it remains nearly as large when mean SWL is added as a control. Since the purported mechanical correlation is caused by high mean SWL, this result demonstrates that the mechanical correlation can only explain a small part of the correlation between the mean and dispersion of the SWL distribution. In our third and final test, we modelled the mapping from actual to reported SWL, enabling us to estimate the distribution of actual SWL in different countries, and compute the correlation between the mean and dispersion of the SWL distribution in actual SWL space. Using this method we estimated that at least two thirds of the observed correlation between the mean and dispersion of reported SWL is real, and that no more than a third of the correlation could be mechanical. Finally, we repeated our main regressions using a purely ordinal measure of dispersion - the variation ratio - confirming that the correlation between SWL levels and SWL dispersion does not depend on the use of a cardinal measure of dispersion.

Our findings support the use of SWL dispersion as a comprehensive measure of inequality. The correlations with SWL levels are much better identified than the corresponding correlations with income inequality, and the mechanical component of the correlation is small. SWL dispersion provides two important advantages for empirical researchers: one conceptual and the other 
practical. The conceptual advantage is that it offers a comprehensive measure of inequality that includes much more than the inequality of income. The practical advantage is consistent measurement in different countries and different periods of time, making it possible to compare the level of inequality in any of the 150 or so countries covered by SWL surveys. We thus hope that our results would encourage other researchers to use SWL dispersion when studying the impact of inequality on subjective well-being.

We conclude by noting that alongside GDP per capita, SWL dispersion can explain a substantial portion of the variance in SWL levels among rich countries. The countries with the highest level of SWL, such as Denmark, are characterized by a high level of GDP per capita and a low SWL dispersion. At the opposite end, countries such as Portugal and Greece are characterized by a low level of GDP per capita and high SWL dispersion. The United States has a GDP per capita as high as Denmark, but a much higher level of SWL dispersion. Its mean SWL level is substantially lower than that of Denmark, and is a little lower than New Zealand - a country with a much lower GDP per capita, but also with a much lower level of SWL dispersion. Needless to say, correlation does not imply causation. But whatever econometric techniques researchers may wish to use, SWL dispersion deserves a place in their toolkit.

\section{REFERENCES}

Alesina, A., Tella, R. D., \& MacCulloch, R. (2004). Inequality and happiness: are Europeans and Americans different? Journal of Public Economics.

Bjørnskov, C. (2007). Determinants of generalized trust: A cross-country comparison. Public choice, 130(1-2), 1-21.

Bolle, F. \& Kemp, S. (2009). Can We Compare Life Satisfaction Between Nationalities? Evaluating Actual and Imagined Situations. Social Indicators Research, 90(3), 397-408.

Bolle, F., Okhrin, Y., \& Vogel, C. (2009). A note on interdependent happiness. Journal of Socio-Economics, 38(5), 713-721.

Burkhauser, R. V., De Neve, J.-E., \& Powdthavee, N. (2016). Top incomes and human well-being around the world. Centre for Economic Performance, LSE.

Case, A. \& Deaton, A. (2015). Rising morbidity and mortality in midlife among white non-hispanic americans in the 21st century. Proceedings of the National Academy of Sciences, 112(49), 15078-15083. 
Clark, A., Frijters, P., \& Shields, M. (2008). Relative Income, Happiness and Utility: An Explanation for the Easterlin Paradox and Other Puzzles. Journal of Economic Literature, 46(1), 95-144.

Deaton, A. (2010). Price indexes, inequality, and the measurement of world poverty. American Economic Review, 100(1), 5-34.

Delhey, J. (2004). Life satisfaction in an enlarged europe. European Foundation for the improvement of Living and Working Conditions.

Di Tella, R. \& MacCulloch, R. (2006). Some uses of happiness data in economics. Journal of Economic Perspectives, 25-46.

Easterlin, R. (1974). Does economic growth improve the human lot? some empirical evidence. In P. A. David \& M. W. Reder (Eds.), Nations and households in economic growth: Essays in honor of moses abramowitz (pp. 89-125). New-York: Academic Press.

Frey, B., Luechinger, S., \& Stutzer, A. (2007). Calculating tragedy: Assessing the costs of terrorism. Journal of Economic Surveys, 21(1), 1-24.

Harsanyi, J. (1955). Cardinal welfare, individualistic ethics, and the interpersonal comparison of utility. Journal of Political Economy, 63, 309-321.

Helliwell, J. F. \& Putnam, R. D. (2004). The social context of well-being. Philosophical Transactions: Biological Sciences, 359(1449), 1435-1446.

Helliwell, J. F. \& Wang, S. (2011). Trust and wellbeing. International Journal of Wellbeing, 1(1), 42-78.

Kalmijn, W. \& Veenhoven, R. (2005). Measuring inequality of happiness in nations: In search for proper statistics. Journal of Happiness Studies, 6(4), 357-396.

Knack, S. \& Keefer, P. (1997). Does social capital have an economic payoff? a cross-country investigation. Quarterly Journal of Economics, 12511288.

Layard, R., Mayraz, G., \& Nickell, S. (2008). The marginal utility of income. Journal of Public Economics, 92(8-9), 1846-1857.

Luttmer, E. F. (2005). Neighbours as negatives: Relative earnings and wellbeing. Quarterly Journal of Economics, 120(3), 963-1002.

Neal, D. \& Rick, A. (2014). The prison boom and the lack of black progress after smith and welch. National Bureau of Economic Research.

Ott, J. (2005). Level and inequality of happiness in nations: Does greater happiness of a greater number imply greater inequality in happiness? Journal of Happiness Studies.

Piketty, T. (2014). Capital in the twenty-first century. Harvard University Press. 
Quick, A. (2015). Inequalities in wellbeing: Challenges and opportunities for research and policy. New Economic Foundation.

Rothstein, B. \& Uslaner, E. M. (2005). All for all: Equality, corruption, and social trust. World Politics, 58(01), 41-72.

Stevenson, B. \& Wolfers, J. (2008). Happiness inequality in the united states. The Journal of Legal Studies, 37(S2), S33-S79.

Stevenson, B. \& Wolfers, J. (2013). Subjective well-being and income: Is there any evidence of satiation? The American Economic Review, 103(3), 598604.

Van Praag, B. \& Baarsma, B. (2005). Using Happiness Surveys to Value Intangibles: The Case of Airport Noise. Economic Journal, 115(500), 224246.

Veenhoven, R. (1990). Inequality in happiness, inequality in countries compared between countries. In Paper 12th work congress of sociology, madrid, spain.

Wang, W. \& Parker, K. (2014). Record share of americans have never married as values, economics and gender patterns change. Pew Research Center.

\section{A THE VARIATION RATIO MEASURE OF SWL DISPERSION}

This appendix includes tables corresponding to those of Section IV.1, but with the ordinal variation ratio measure of SWL dispersion instead of the cardinal standard deviation used in Section IV.1. If the correlation between SWL levels and the standard deviation of SWL is an artifact of the reporting scale, we would expect the correlation to disappear when using an ordinal measure of dispersion, such as the variation ratio. Instead, we find essentially the same results as in Section IV.1. Of course, since the variation ratio is a noisier measure of dispersion, we can expect the correlation between SWL levels and SWL dispersion to be somewhat weaker. Moreover, when both SWL dispersion and the Gini coefficient of income are included in the same regression, we can expect the correlation between SWL levels and the Gini coefficient of income to be weaker. This is exactly what we find. 
Table 9: SWL and inequality regressions in the European Social Survey with the variation ratio measure of SWL dispersion ${ }^{a}$

\begin{tabular}{|c|c|c|c|c|c|}
\hline & \multicolumn{5}{|c|}{ Dependent variable: life satisfaction $(0-10)$} \\
\hline & (1) & (2) & (3) & (4) & $(5)$ \\
\hline $\begin{array}{l}\text { SWL } \\
\text { variation ratio } b\end{array}$ & $\begin{array}{l}-0.16^{* * *} \\
(-7.75)\end{array}$ & & $\begin{array}{l}-0.14^{* * *} \\
(-6.91)\end{array}$ & $\begin{array}{l}-0.11^{* * *} \\
(-5.71)\end{array}$ & $\begin{array}{l}-0.04^{*} \\
(-2.37)\end{array}$ \\
\hline $\begin{array}{l}\text { Income } \\
\text { Gini coef. }{ }^{b}\end{array}$ & & $\begin{array}{l}-0.07^{* *} \\
(-3.33)\end{array}$ & $\begin{array}{c}-0.04 \\
(-1.91)\end{array}$ & $\begin{array}{l}-0.05^{* *} \\
(-2.71)\end{array}$ & $\begin{array}{l}-0.04^{*} \\
(-2.25)\end{array}$ \\
\hline $\begin{array}{l}\text { GDP per capita } \\
\text { in } \log \text { terms } b\end{array}$ & $\begin{array}{l}0.23^{* * *} \\
(11.40)\end{array}$ & $\begin{array}{l}0.33^{* * *} \\
(19.21)\end{array}$ & $\begin{array}{l}0.24^{* * *} \\
(11.53)\end{array}$ & $\begin{array}{c}0.20^{* * *} \\
(9.93)\end{array}$ & $\begin{array}{c}0.39^{* * *} \\
(6.68)\end{array}$ \\
\hline $\begin{array}{l}\text { Thinks inequality } \\
\text { is too } \operatorname{high}^{c}\end{array}$ & & & & $\begin{array}{c}0.12 \\
(1.85)\end{array}$ & $\begin{array}{l}0.11^{* *} \\
(3.18)\end{array}$ \\
\hline $\begin{array}{ll} & \text { SWL } \\
& \mathrm{VR}\end{array}$ & & & & $\begin{array}{c}-0.37^{* * *} \\
(-6.11)\end{array}$ & $\begin{array}{c}-0.27^{* * *} \\
(-9.52)\end{array}$ \\
\hline $\begin{array}{ll}\times \quad \text { Income } \\
\text { Gini coef. }\end{array}$ & & & & $\begin{array}{l}0.15^{*} \\
(2.53)\end{array}$ & $\begin{array}{c}0.08 \\
(1.84)\end{array}$ \\
\hline Country dummies & & & & & Yes \\
\hline No. of observations & 303853 & 301960 & 301960 & 301960 & 301960 \\
\hline $\begin{array}{l}{ }^{a} \text { Standardised beta coeffi } \\
\text { Statistical significance in } \\
\text { Clusters defined by cour } \\
{ }^{b} \text { Cluster level variables: } \\
{ }^{c} 5 \text { level variable indicatir } \\
\text { values indicate agreeme } \\
{ }^{d} \text { Gender, age, age square }\end{array}$ & $\begin{array}{l}\text { ents; } t \text { stati } \\
\text { licators: }{ }^{*} p \\
\text { y/wave cor } \\
g_{i} \text {, and } Y_{i} \\
\text { individual } \\
\text { and negati } \\
\text { education }\end{array}$ & $\begin{array}{l}\text { cs correctec } \\
0.05,{ }^{* *} p \\
\text { pination. } \\
\text { the text. } \\
\text { reference fo } \\
\text { values disa } \\
\text { ummies) ar }\end{array}$ & $\begin{array}{l}\text { for clusteri } \\
0.01,{ }^{* * *} p \\
\text { equality ( } e \\
\text { reement. }\end{array}$ & $\begin{array}{l}\text { in parenthe } \\
0.001 . \\
\text { in the text). }\end{array}$ & $\begin{array}{l}\text { es. } \\
\text { ositive }\end{array}$ \\
\hline
\end{tabular}


Table 10: SWL and inequality regressions in the World Values Survey with the variation ratio measure of $\mathrm{SWL}^{a}$

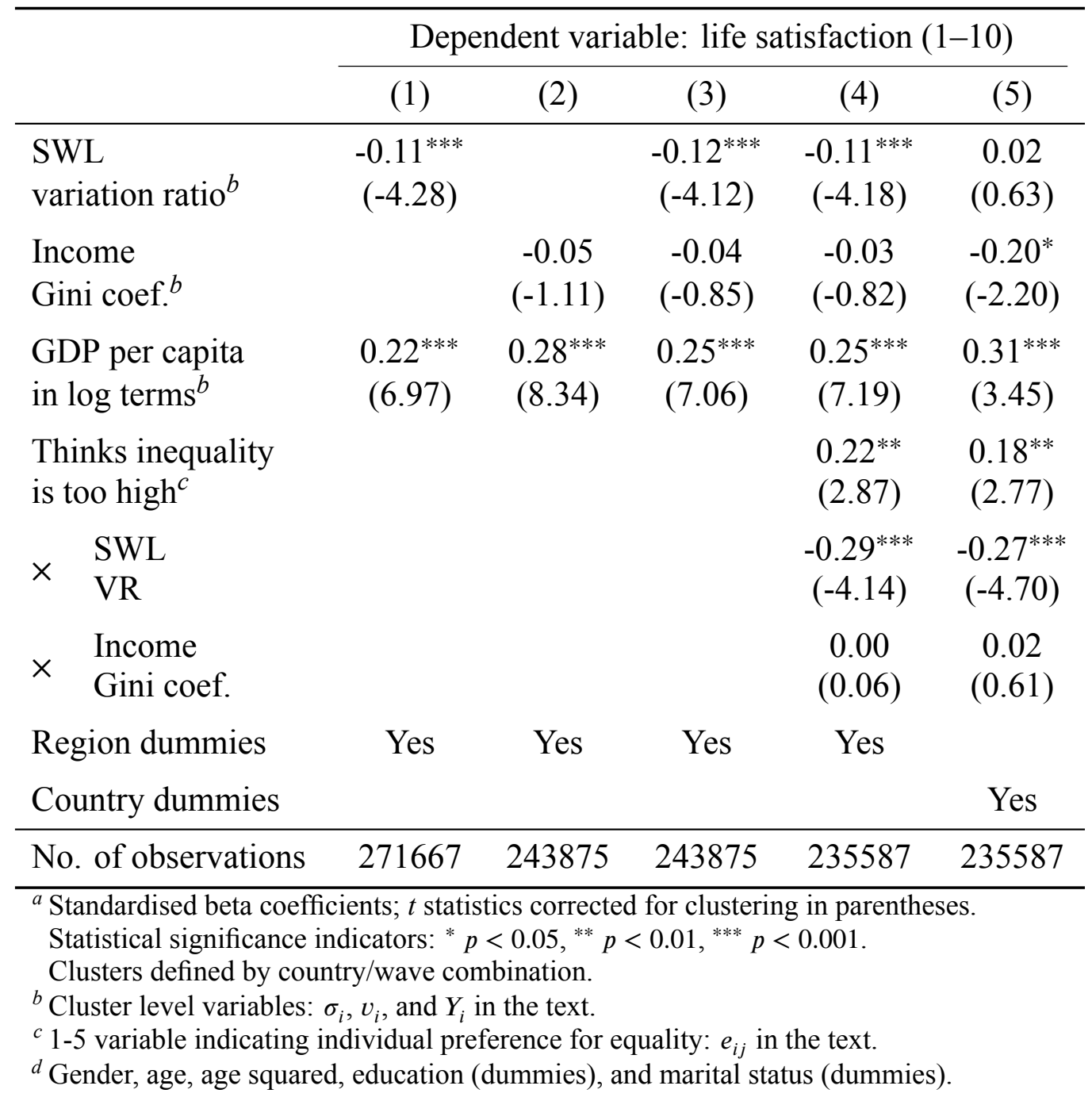


Table 11: SWL and inequality regressions in the Gallup World Poll with the variation ratio of SWL dispersion ${ }^{a}$

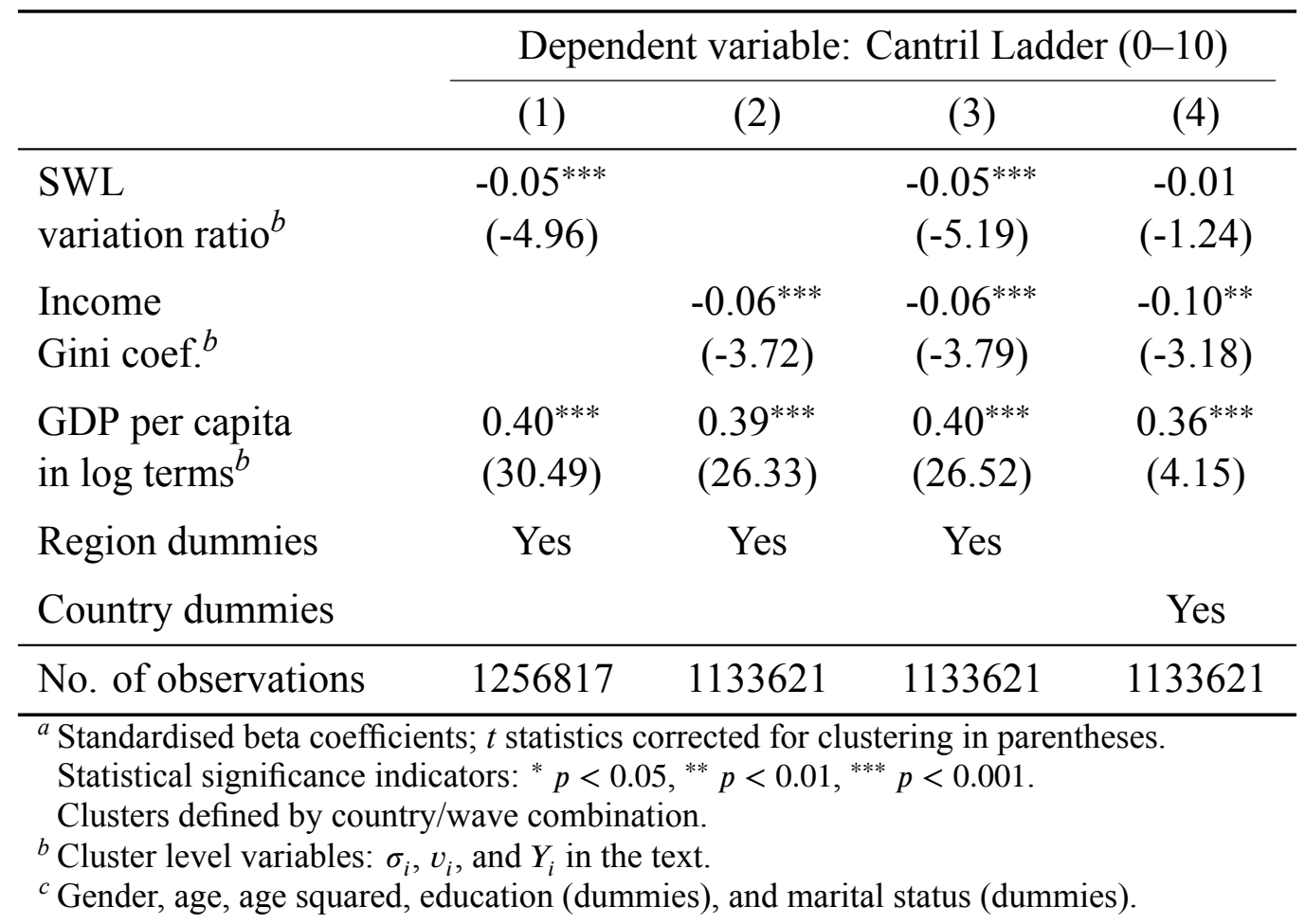


Table 12: SWL and inequality regressions in the Gallup-Healthways Well-Being Index with the variation ratio measure of SWL dispersion ${ }^{a}$

\begin{tabular}{|c|c|c|c|c|}
\hline & \multicolumn{4}{|c|}{ Dependent variable: Cantril ladder $(0-10)$} \\
\hline & (1) & (2) & (3) & (4) \\
\hline $\begin{array}{l}\text { SWL } \\
\text { variation ratio }\end{array}$ & $\begin{array}{l}-0.08^{* * *} \\
(-18.31)\end{array}$ & & $\begin{array}{l}-0.08^{* * *} \\
(-19.65)\end{array}$ & $\begin{array}{l}-0.09 * * * \\
(-35.85)\end{array}$ \\
\hline $\begin{array}{l}\text { Income } \\
\text { Gini coef. } b\end{array}$ & & $\begin{array}{c}0.01 \\
(1.12)\end{array}$ & $\begin{array}{c}0.02^{* * *} \\
(4.57)\end{array}$ & $\begin{array}{c}0.03^{* * *} \\
(3.43)\end{array}$ \\
\hline $\begin{array}{l}\text { GDP per capita } \\
\text { in } \log \text { terms } b\end{array}$ & $\begin{array}{c}-0.00 \\
(-0.53)\end{array}$ & $\begin{array}{l}-0.00 \\
(-0.36)\end{array}$ & $\begin{array}{c}-0.00 \\
(-0.53)\end{array}$ & $\begin{array}{l}-0.00 \\
(-0.11)\end{array}$ \\
\hline State dummies & & & & Yes \\
\hline No. of observations & 1363274 & 1363274 & 1363274 & 1363274 \\
\hline
\end{tabular}

